\title{
Schweigen? Nicht immer
}

- Vor Kurzem ist die Oma meiner Freundin ganz plötzlich gestorben. Ihre Schwester war zu diesem Zeitpunkt im Urlaub in Malaysia. Der Großteil der Familie wollte ihr nichts sagen - sie sollte den Urlaub genießen und nicht früher wegen der Beerdigung nach Hause fliegen müssen. Die Entscheidung war gut gemeint, allerdings ganz und gar nicht im Sinne der Schwester - und hatte auch keinen Bestand. Denn via Facebook bekam die Ahnungslose Beileidsbekundungen von Freunden und Bekannten nach Malaysia geschickt und rief völlig verwirrt zu Hause an. Die Familie musste das Schweigen brechen. Die Schwester flog zwei Tage früher heim und konnte bei der Beerdigung dabei sein. In diesem Fall wäre Schweigen Silber und Reden


Gold gewesen.

_ In der Therapie sieht das ein wenig anders aus. Da gilt in den meisten Fällen „Schweigen ist Gold“ ( $\odot$ „Schweigepflicht“, S. 46). Wenn ein Patient nicht gefragt werden kann, ob er mit der Weitergabe von Informationen einverstanden ist, ist Einfühlungsvermögen gefragt. Denn in diesem Fall muss man mutmaßen, wie sich der Patient im Falle einer Befragung entscheiden würde - eine schwere Aufgabe. Sich zu überlegen, was man sich selbst in dieser Situation wünschen würde, hilft. Hätte das beispielsweise die Familie meiner Freundin gemacht, hätte sie mit Sicherheit einen anderen Entschluss gefasst ...

Herzlichst, Ihre
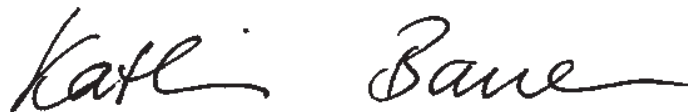

Uuups, verplappert!

Therapeuten sollte

das nicht passieren -

sie müssen die

Schweigepflicht

einhalten. Privat sieht das

manchmal anders aus ...

\section{ZU GEWINNEN}

In jeder physiopraxis werden attraktive Gewinne verlost. Möchten Sie einen ergattern, klicken Sie unter www.thieme.de/physiopraxis auf „Gewinnspiel“.

Und das gibt es in dieser Ausgabe zu gewinnen:

Bücher

2-mal „Tests und Übungen für die Wirbelsäule“

Seite 43

und außerdem

1 Luftbefeuchter

Seite 31

1 Schultermodell

Seite 36

1 Kursplatz „Manuelle Lymphdrainage“

Seite 52

2 Jogging-Gürtel für Smartphones

Seite 57 